\title{
Brine Generation Study
}

\author{
April 2000
}

Waste Isolation Pilot Plant

Carlsbad, New Mexico

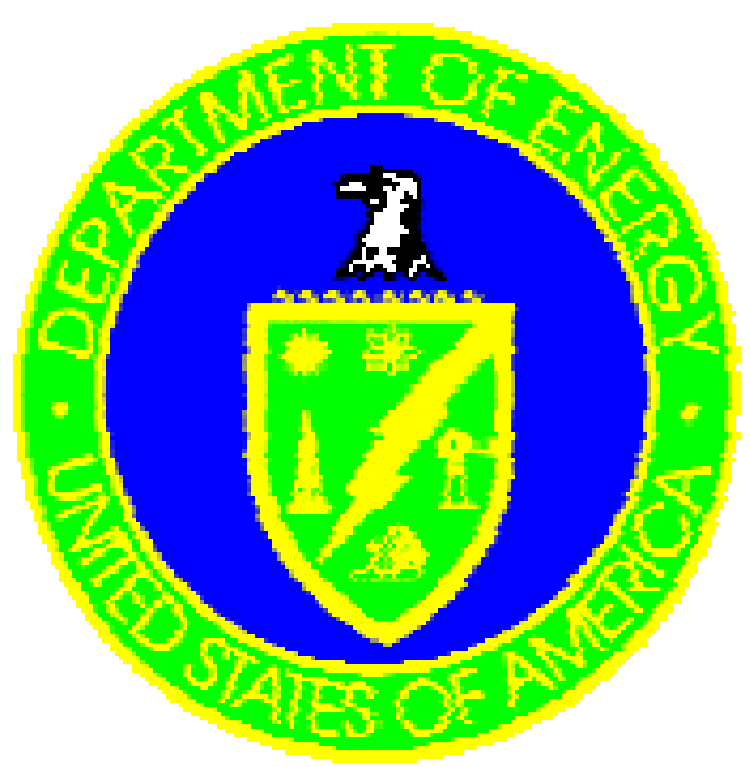

Processing and final preparation of this report was performed by the Waste Isolation Pilot Plant Management and Operating Contractor for the U. S. Department of Energy under Contract No. DE-AC04-86AL31950 


\section{TABLE OF CONTENTS}

LIST OF FIGURES $\ldots \ldots \ldots \ldots \ldots \ldots \ldots \ldots \ldots \ldots \ldots \ldots \ldots \ldots \ldots \ldots \ldots \ldots \ldots \ldots$

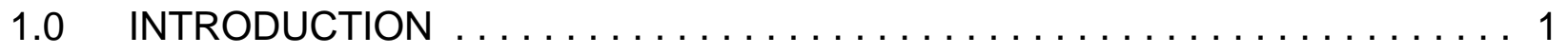

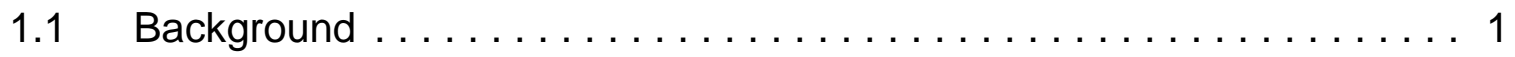

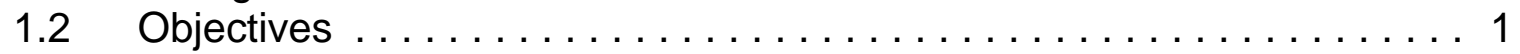

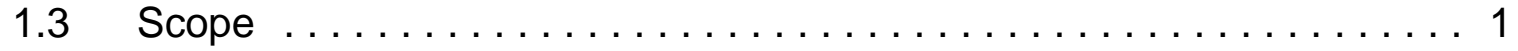

1.4 Data Presentation $\ldots \ldots \ldots \ldots \ldots \ldots \ldots \ldots \ldots \ldots \ldots \ldots$

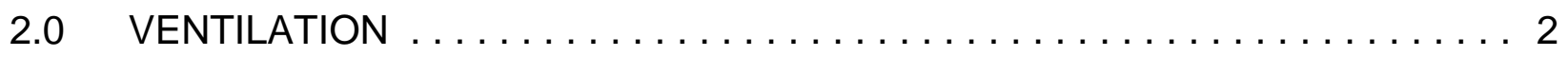

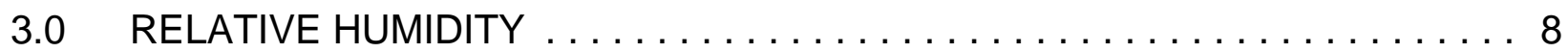

4.0 CATCH BASIN FLOW $\ldots \ldots \ldots \ldots \ldots \ldots \ldots \ldots \ldots \ldots \ldots \ldots \ldots \ldots \ldots \ldots$



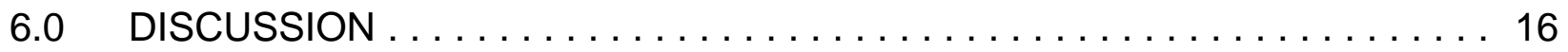






\section{LIST OF FIGURES}

Figure 2-1 - Exhaust Shaft Airflow, June 1, 1998 - October 31, $1999 \ldots \ldots \ldots \ldots 4$

Figure 2-2 - Exhaust Shaft Airflow, June 1 - October 31, $1998 \ldots \ldots \ldots \ldots \ldots \ldots$

Figure 2-3 - Exhaust Shaft Airflow, May 1 - August 1, $1999 \ldots \ldots \ldots \ldots \ldots$

Figure 2-4 - Hours of No Airflow and Reduced Airflow, June 1, 1998 -

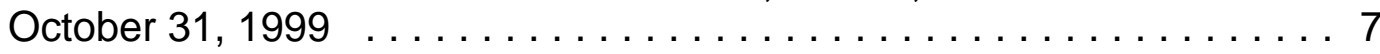

Figure 3-1 - Average, Minimum, and Maximum Relative Humidity Values, June 1, 1998 - October $31,1999 \ldots \ldots \ldots \ldots \ldots \ldots \ldots \ldots$

Figure 3-2 - Average, Minimum, and Maximum Relative Humidity Values, June 1 -

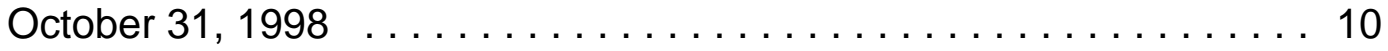

Figure 3-3 - Average, Minimum, and Maximum Relative Humidity Values, May 1 August1, $1999 \ldots \ldots \ldots \ldots \ldots \ldots \ldots \ldots \ldots \ldots \ldots \ldots \ldots \ldots$

Figure 4-1 - Volume of Fluid Removed from the Catch Basin, June 1, 1998 October 31, 1999

Figure 5-1 - WIPP Site Precipitation, June 1, 1998 - October 31, 1999 . . . . . . 15

Figure 6-1 - Comparison of Ventilation, Precipitation, and Catch Basin Data, June 1 - October $31,1998 \ldots \ldots \ldots \ldots \ldots \ldots \ldots \ldots \ldots \ldots$

Figure 6-2 - Hours of No Airflow, Reduced Airflow, Precipitation, and Catch Basin Data, June 1 - October 31, $1998 \ldots \ldots \ldots \ldots \ldots \ldots \ldots \ldots \ldots \ldots$

Figure 6-3 - Comparison of Relative Humidity, Precipitation, and Catch Basin Data, June 1 - October 31, $1998 \ldots \ldots \ldots \ldots \ldots \ldots \ldots \ldots \ldots \ldots$

Figure 6-4 - Airflow, Hours No Flow, Reduced Airflow, Precipitation, and Catch Basin Data, May 1 - August 1, 1999 . . . . . . . . . . . . . . 23

Figure 6-5 - Relative Humidity, Precipitation, and Catch Basin Data, May 1 -

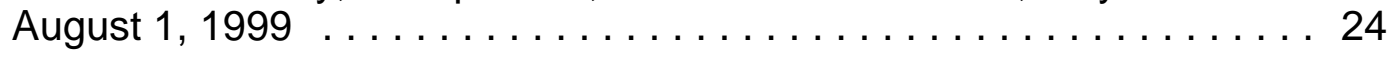

Figure 6-6 - Airflow and Catch Basin Data, June 1, 1998 - October 31, 1999 . . . 25

Figure 6-7 - Airflow, Catch Basin, and Precipitation Data, November 1, 1998 -

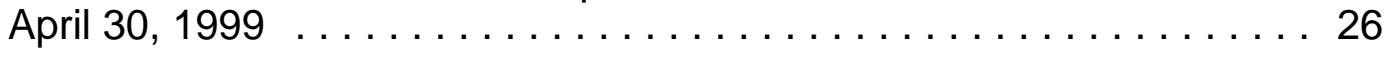

Figure 6-8 - Relative Humidity, Precipitation, and Catch Basin Data, November 1, 1998 - April 30, 1999 


\subsection{INTRODUCTION}

\subsection{Background}

In a May 1995 inspection of the WIPP-site Exhaust Shaft indicated that water was seeping through the shaft's concrete liner at depths of 50 to 85 feet below ground surface. In March 1996 a catch basin was installed at the base of the Exhaust Shaft to intercept and prevent fluid from entering the repository horizon. Analyses of fluid samples collected from the catch basin indicated that some samples had concentration levels that exceeded U.S. Environmental Protection Agency (EPA) toxicity characteristics for lead under Title 40 Code of Federal Regulations (CFR) § 261.24. Ventilation system operations, weather conditions, and seepage into the Exhaust Shaft have resulted in operational problems. First, increased moisture in the shaft has affected air filters on sampling probes located near the top of the Exhaust Shaft, thus preventing analysis of air samples. Second, production of fluid in the shaft reporting to the catch basin created a disposal problem of the fluid which has been classified as a hazardous material under 40 CFR $\S 261.24$ for lead. Though these problems do not effect the stability of the shaft they are a nuisance in that they increase operational costs and impact operation of the Exhaust Shaft air-monitoring system.

\subsection{Objectives}

The objective of this report is to examine those factors effecting the quantity of fluid reporting to the Exhaust Shaft Catch Basin; determine their relative importance; and determine what measures can be implemented to reduce operational problems in the Exhaust Shaft.

\subsection{Scope}

Five parameters (airflow, ventilation system operation, relative humidity, precipitation, and the quantity of fluid reporting to the catch basin) were examined over a 17-month period extending from June 1998 through October 1999. Plots of the data were intended to provide sufficient detail to establish trends between parameters. There are, however, limitations in the data due to the data availability, the sampling frequency, and the extreme variability of some parameter values over short intervals of time (e.g., relative humidity) and correlating the data to specific events.

\subsection{Data Presentation}

Data is presented in several formats. Air ventilation data, based on entries manually recorded in the WIPP-site Central Monitoring Room (CMR) logbook are presented as daily average flow rates in units of cubic feet per minute (CFM). Ventilation system operations examines the number of hours during the course of a day during which there is either no airflow or reduced airflow conditions in the Exhaust Shaft. Prolonged periods of no and/or reduced airflow increases the probability of fluid reporting to the catch basin. Relative humidity data are measured at the WIPP site Weather Station and presented in the form of high-low-close plots providing the average and the minimum and maximum relative humidity values for each day. Since the relative 
humidity can vary by as much as 80 percent or more over the course of a 24-hour period, daily average relative humidity values do not adequately portray the conditions in the shaft at any given time. Therefore, relative humidity values include not only the average but also the high-low values for each day.

The volume of fluid removed from the catch basin is measured and recorded in units of gallons. Fluid is removed from the catch basin Monday through Friday, if required. Care must be taken in examining and interpreting catch-basin data in that there may be a multi-day lag time between the time fluid reports to the catch basin and the time in which the fluid is actually removed. Precipitation is the last of the five variables presented. Precipitation is measured at the WIPP site Weather Station and reported in units of millimeters of rainfall per day. For this report precipitation is presented in English units of inches.

\subsection{VENTILATION}

This section discusses Exhaust Shaft airflow measurements collected between June 1, 1998, and October 31, 1999. Measurements were collected by Central Monitoring Room personnel at the WIPP and recorded in the CMR logbook. Data is based on the following fan operations: one 700 fan operating at 260,000 CFM, two 700 fans operating at 425,000 CFM, one 860 fan operating at 60,000 CFM, and two 860 fans operating at 120,000 CFM. Figure 2-1 is a plot of airflow versus time for the period extending from June 1998 through October 1999. The average daily airflow rate for the 17-month period was $274,000 \mathrm{CFM}$. The plot is divided into three time intervals extending from June 1, 1998, through October 31, 1998; November 1, 1998, through April 30, 1999; and May 1 through October 31, 1999. The daily average airflow rate for each of the three periods was $216,000,256,000$ and 343,000 CFM, respectively.

Figures 2-2 and 2-3 are plots of average daily airflow versus time for the periods extending from June 1 through October 31, 1998, and May 1 through August 1, 1999, respectively. These two periods are of particular interest in that 95 percent of the total volume of fluid that reported to the catch basin during the seventeen-month period occurred during these two windows of time. It is clear from Figures 2-2 and 2-3 that the most common ventilation mode was 260,000 CFM (referred to as alternate mode). Figure 2-2 shows that there were 58 days during the June through October 1998 time period where the average airflow rate dropped below 200,000 CFM. Figure 2-3 shows that there was only one day during the May through August 1999 time period when the airflow dropped below 200,000 CFM. Figure 2-3 also shows that there were significant periods of time where the shaft ventilation system was operating with two 700 -fans at 425,000 CFM.

A second way of viewing Exhaust Shaft ventilation data is to examine the number of hours during the day in which there was either no airflow or reduced airflow conditions in the shaft. Reduced airflow is when the ventilation system is operating on one or two 860 fans $(60,000$ or 120,000 CFM, respectively). Extended periods of no airflow provide favorable conditions for fluid seeping into the Exhaust Shaft to migrate down the shaft walls unabated and report to the catch basin. Reduced airflow conditions result in a decrease in the capacity of the air to carry and to remove fluid from the shaft. 
Therefore, extended periods of reduced airflow can also provide favorable conditions for fluid to report to the catch basin.

Figure 2-4 is a plot of hours of no airflow and reduced airflow verses time for the entire seventeen-month period. The plot identifies over 30 no airflow and 90 reduced airflow events ranging from $1 / 2$-hour to 24 -hours in duration. Approximately 60 percent of the events occurred between June 1 and October 31, 1998. Another 30 percent occurred between November 1, 1998, and April 30, 1999, with the remaining 10 percent occurring between May 1 and October 31, 1999. 


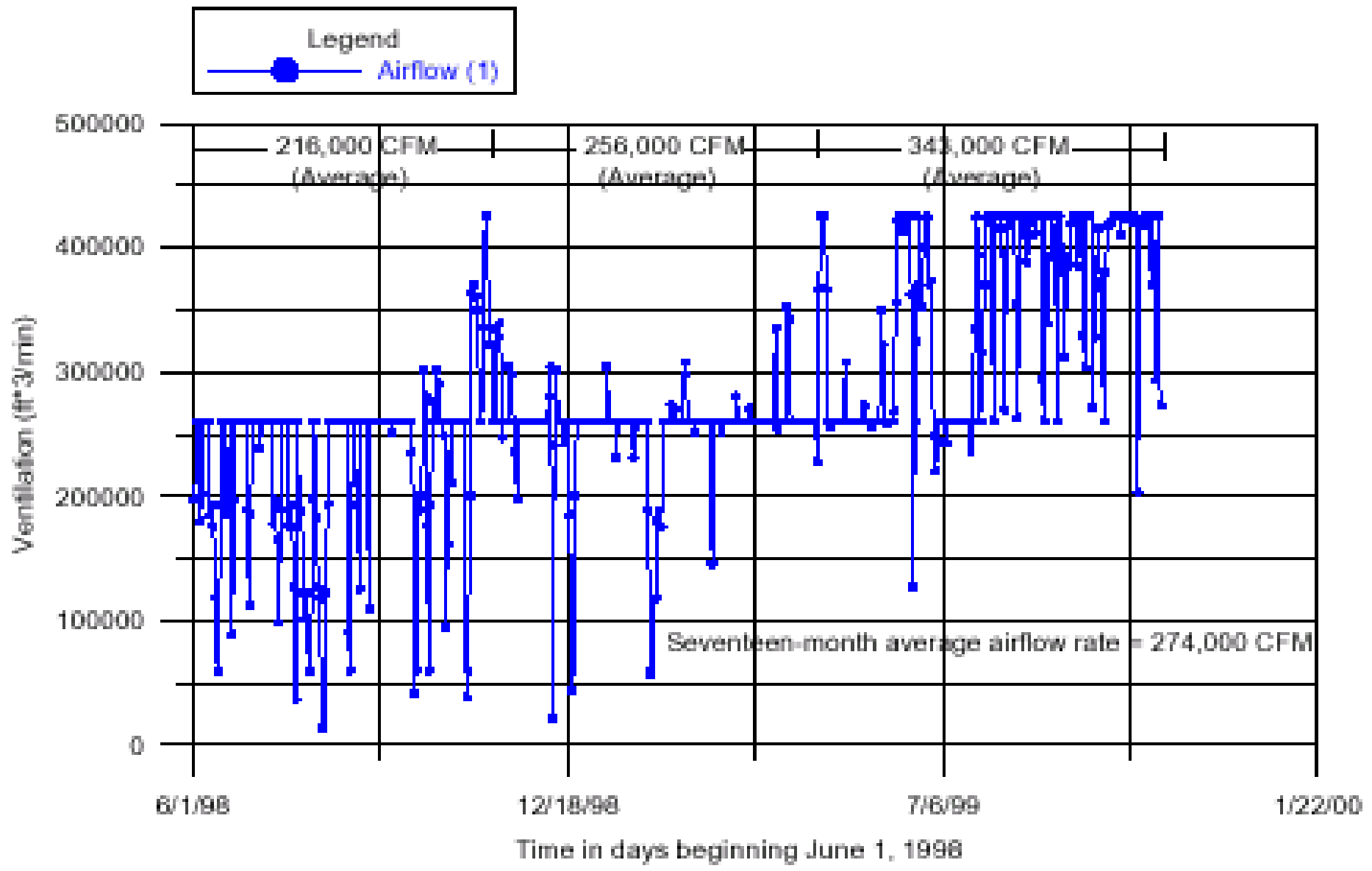

Figure 2-1. Exhaust Shaft airflow. June 1, 1998 - October 31, 1999 


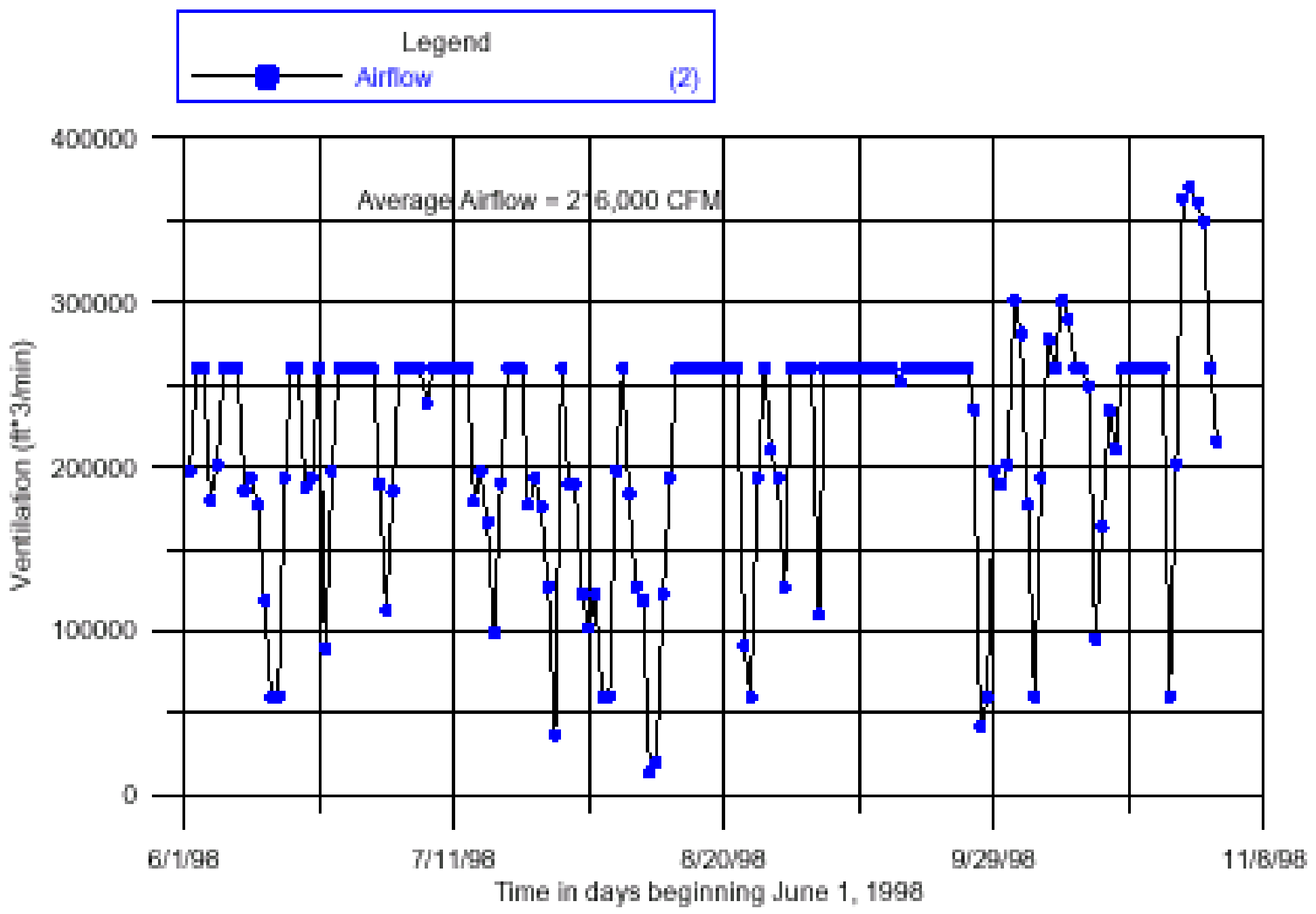

Figure 2-2. Exhaust Shaft airflow: June 1-October 31, 1996 


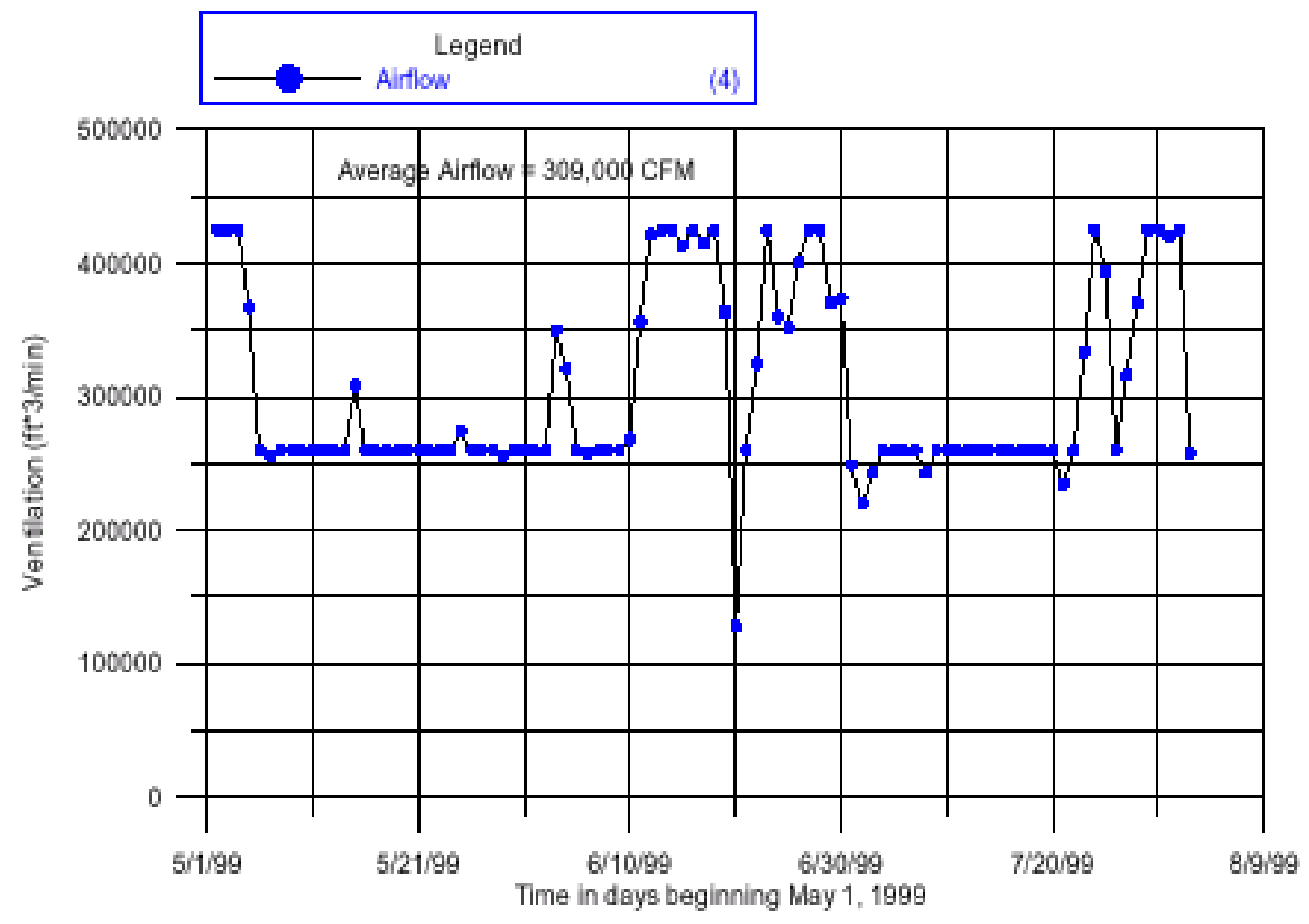

Figure 2-3. Exhaust shaft airflow: May 1 - August 1, 1999 


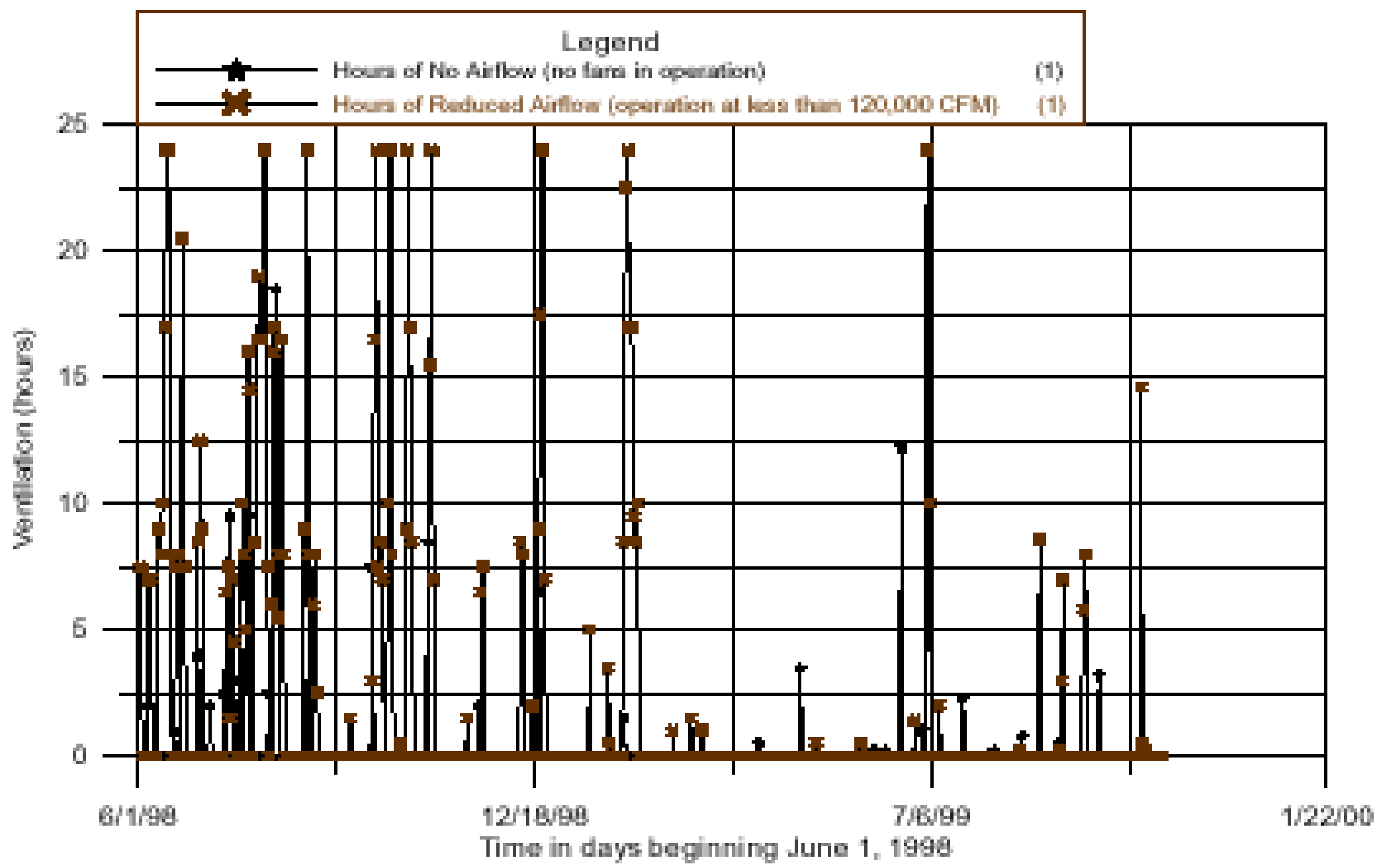

Figure 2-4. Hours of no airflow and roduced airflow: June 1, 1998 - Oetober 31, 1999 


\subsection{RELATIVE HUMIDITY}

Relative humidity measurements were collected from the WIPP site Weather Station. Relative humidity values were measured at fifteen-minute intervals and averaged over 24-hour periods. Daily averages and daily high and low values are presented in Figure 3-1 for the period extending from June 1, 1998 through October 31, 1999. Due to the density of the data only high and low values can be distinguished from the plot. The data is so dense that the average values cannot be distinguished. Figures 3-2 and 3-3 provide a more detailed plot of the average, high and low values for the periods extending from June 1 through October 31, 1998, and May 1 through August 1, 1999, respectively. The figures show that relative humidity values can vary by as much as 80 percent for a 24-hour period. Therefore, care must be taken in using just average relative humidity as a measure of the conditions in the shaft because it does not portray the variability experienced at the site. Daily averages tend to mask discrete high humidity events, like thunderstorms, where the humidity may be high for only a brief period of time. High-low plots are useful in that they not only provide the average relative humidity, but also define conditions of high humidity when precipitation is likely to occur. Between June 1 and October 31, 1998, there were 38 days out of 152 where the relative humidity exceeded 90 percent during the course of the day. Between May 30 and August 1, 1999, there were 18 days out of 93 when the relative humidity exceeded 90 percent.

During prolonged periods of high humidity the shaft wall moisture content increases. As the walls saturate, less fluid is absorbed making more fluid available to report to the catch basin and/or be removed through the ventilation system. On the other hand, during periods of low humidity the shaft walls decrease in moisture content increasing the capacity of the walls to store fluid. The capacity of the shaft walls to absorb and lose water can result in a time lag for fluid reporting to the catch basin that is difficult to quantify. 


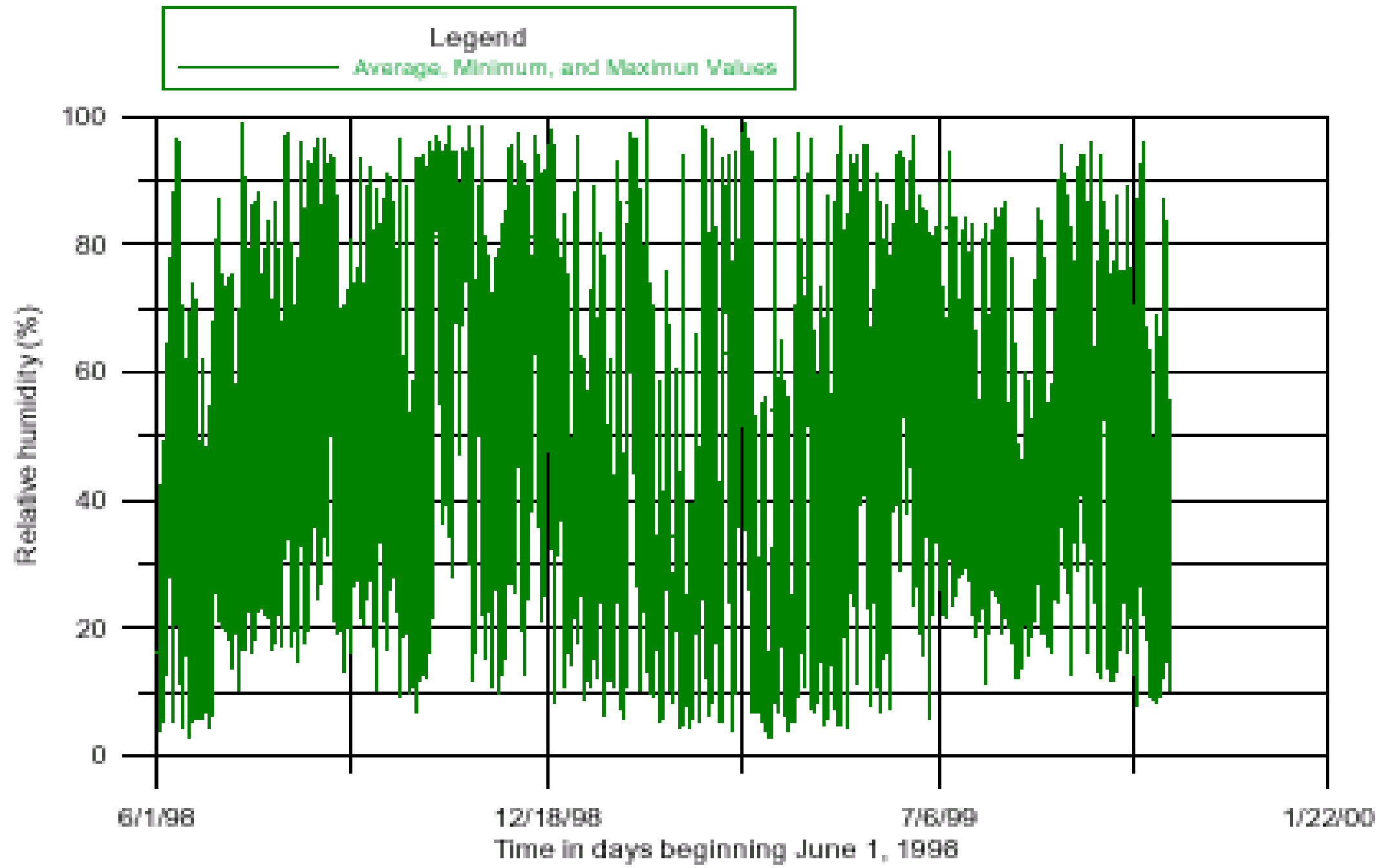

Figure 3-1. Average, minimum, and maximum relative humidity values: June 1- Oetober 31,1999 


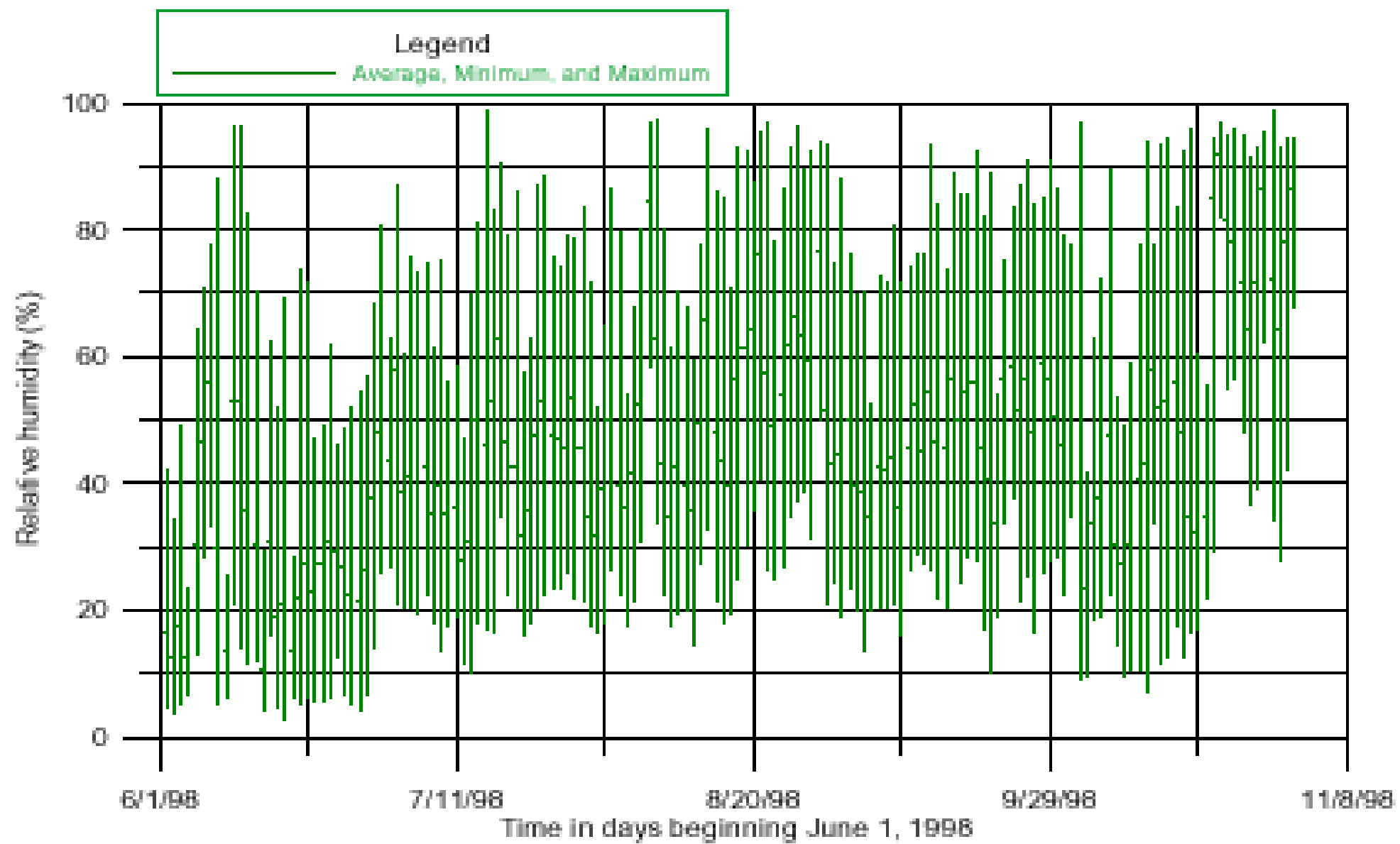

Figure 3.2. Average, minimum, and maximum relative humidity values: June 1 - October 31 , 1996 


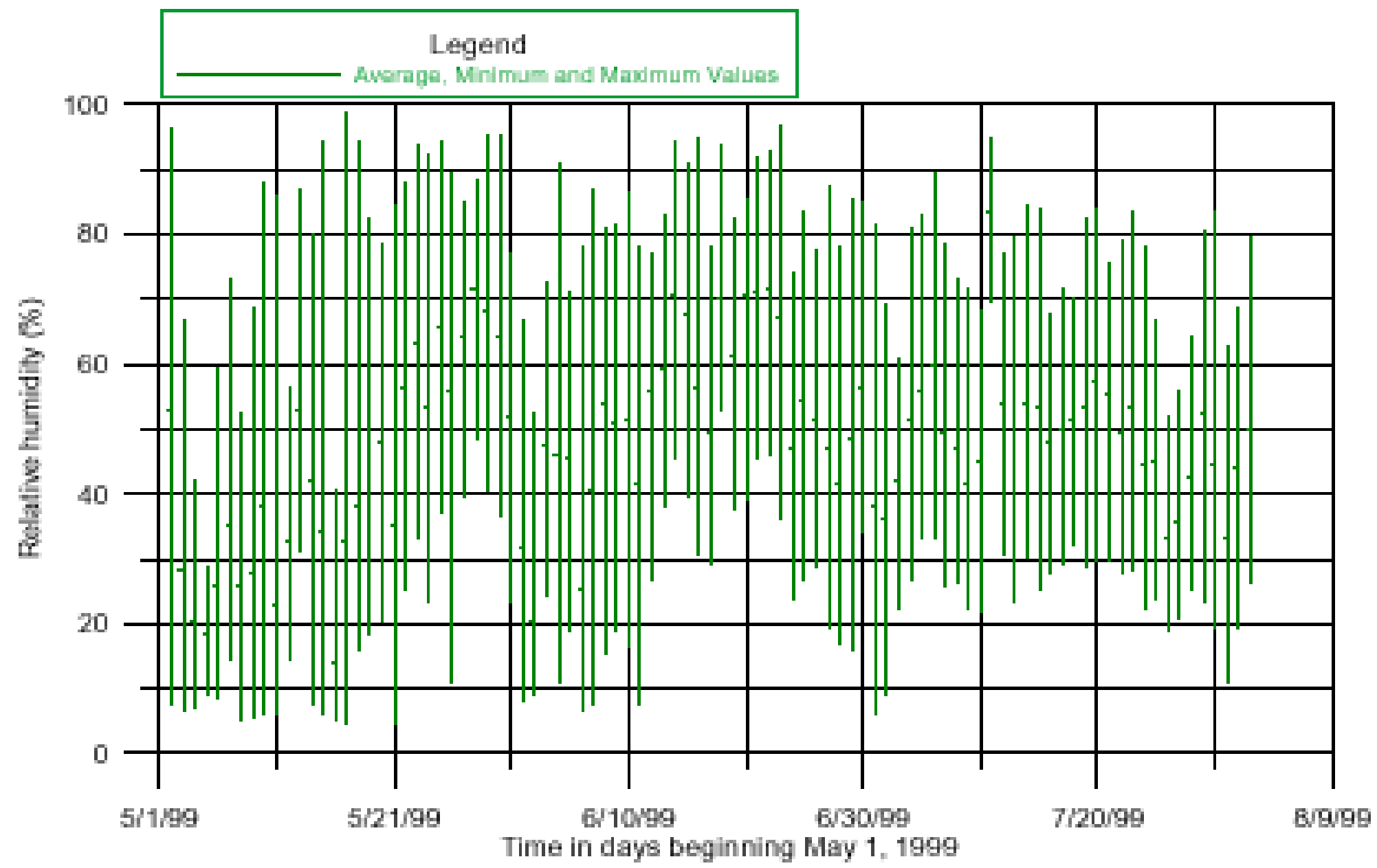

Figure 3.3. Average, minimum, and maximum relative humidity values: Vay 1 in Octobor 31, 1999 


\subsection{CATCH BASIN FLOW}

Water enters the Exhaust Shaft through three paths. First, water enters the Exhaust Shaft through cracks or construction joints in the shaft liner. Depending on operating conditions, this water can migrate down the shaft walls into the catch basin, be absorbed into the shaft wall, or be captured in the airflow and expelled into the atmosphere through the fans. A second source of water in the shaft involves the cooling of warm, moisture-laden air from the WIPP underground facility as it rises up the Exhaust Shaft. Under certain temperature and humidity conditions water may precipitate. Again, this water can flow down the shaft wall, rain into the catch basin, be absorbed into the shaft wall, or removed through the ventilation system. Third, a small amount of geologic water may be entering the shaft. The sources of these waters have been grouted off and if geologic waters are present they are undetectable and being masked totally by the other two sources.

When fluid was detected seeping into the Exhaust Shaft in 1995, a catch basin was designed and installed at the base of the Exhaust Shaft to intercept and prevent water from draining into the Waste Shaft sump. The catch basin consists of two $1^{\prime} \times 9^{\prime} \times 28^{\prime}$ polyethylene reservoirs at the base of the Exhaust Shaft. Fluid has been removed on an as-needed basis from the Exhaust Shaft Catch Basin since March 1996. Figure 4-1 is a plot of the volume of fluid removed from the catch basin between June 1, 1998, and October 31, 1999. The plot indicates there were 33 events in which fluid was removed from the catch basin. The total volume of fluid removed during the 17-month period amounted to over 14,000 gallons. Twenty events occurred between June 1 and October 31,1998 , resulting in the removal of 9,715 gallons. Three events occurred between November 1, 1998 and April 30, 1999, resulting in the removal of 605 gallons. Thirteen events occurred between May 1 and October 31, 1999, resulting in the removal of 4,730 gallons.

Care must be taken in interpreting catch basin data in that no underground work activity is performed in the repository on weekends. Therefore, it is possible that fluid can report to the catch basin as early as Friday, or even earlier, which would not be removed from the catch basin until the following Monday or until sufficient fluid is present to allow its removal by pumping. 


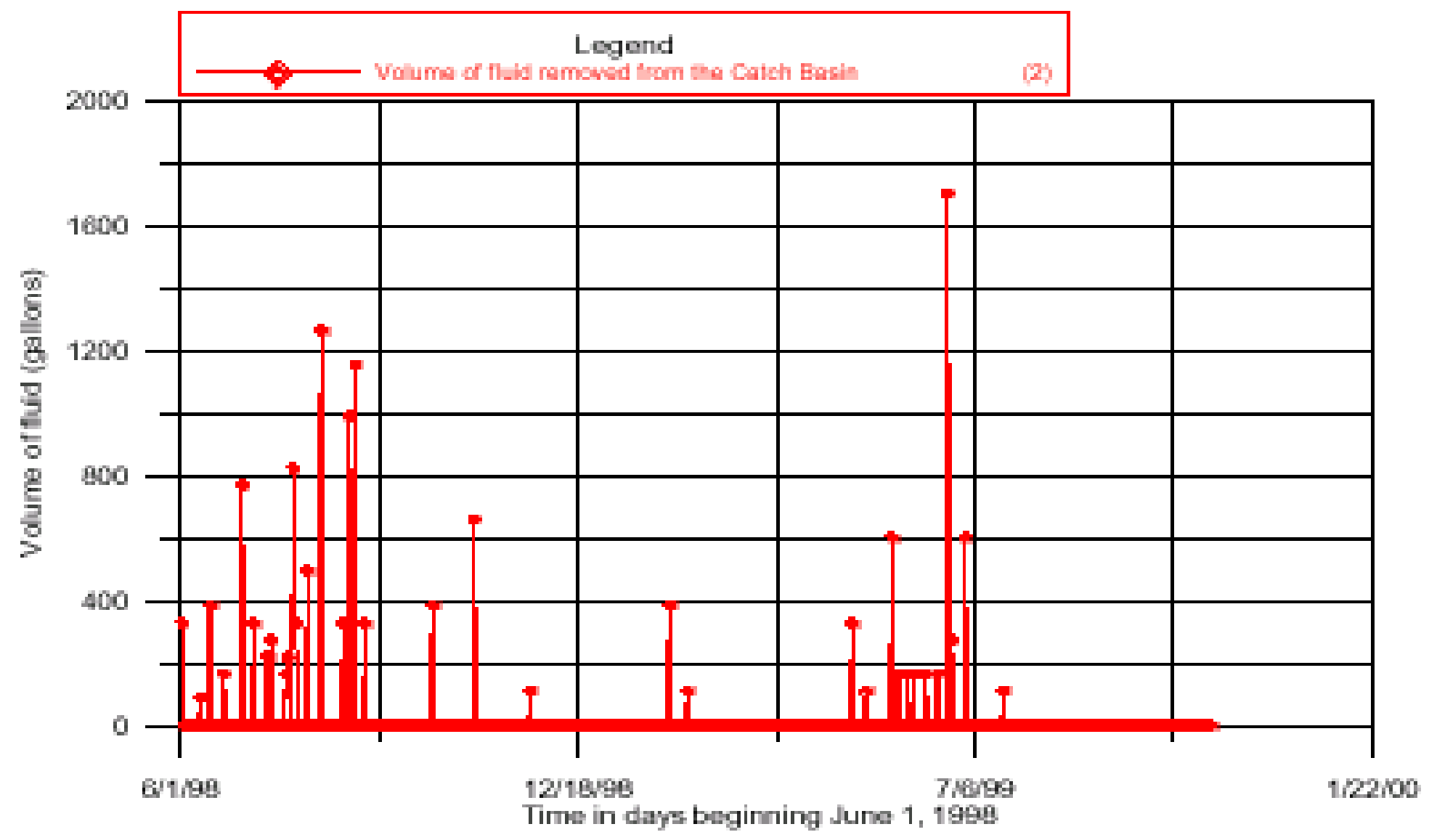

Figure 4-1. Volume of fluid removed from the catch basin: June 1, 1999 - October 31,1999 


\subsection{PRECIPITATION}

Precipitation data is collected daily from the WIPP Weather Station. Figure 5-1 is a plot of the precipitation measured in inches of rainfall for the period extending from June 1, 1998, to October 31, 1999. The plot identifies 59 days in which rainfall occurred ranging in magnitude from 0.01 to 0.90 inches. Twenty-one events occurred between June 1 and October 31, 1998, resulting in a total accumulation of 5.0 inches of rain. Thirteen events occurred between November 1, 1998, and April 30, 1999, resulting in a total accumulation of 2.2 inches of rain. Twenty-five events occurred between May 1 and October 31, 1999, resulting in 6.3 inches of rain. Precipitation cannot fall directly into the Exhaust Shaft, but is relative here in so much as it can increase the relative humidity. 


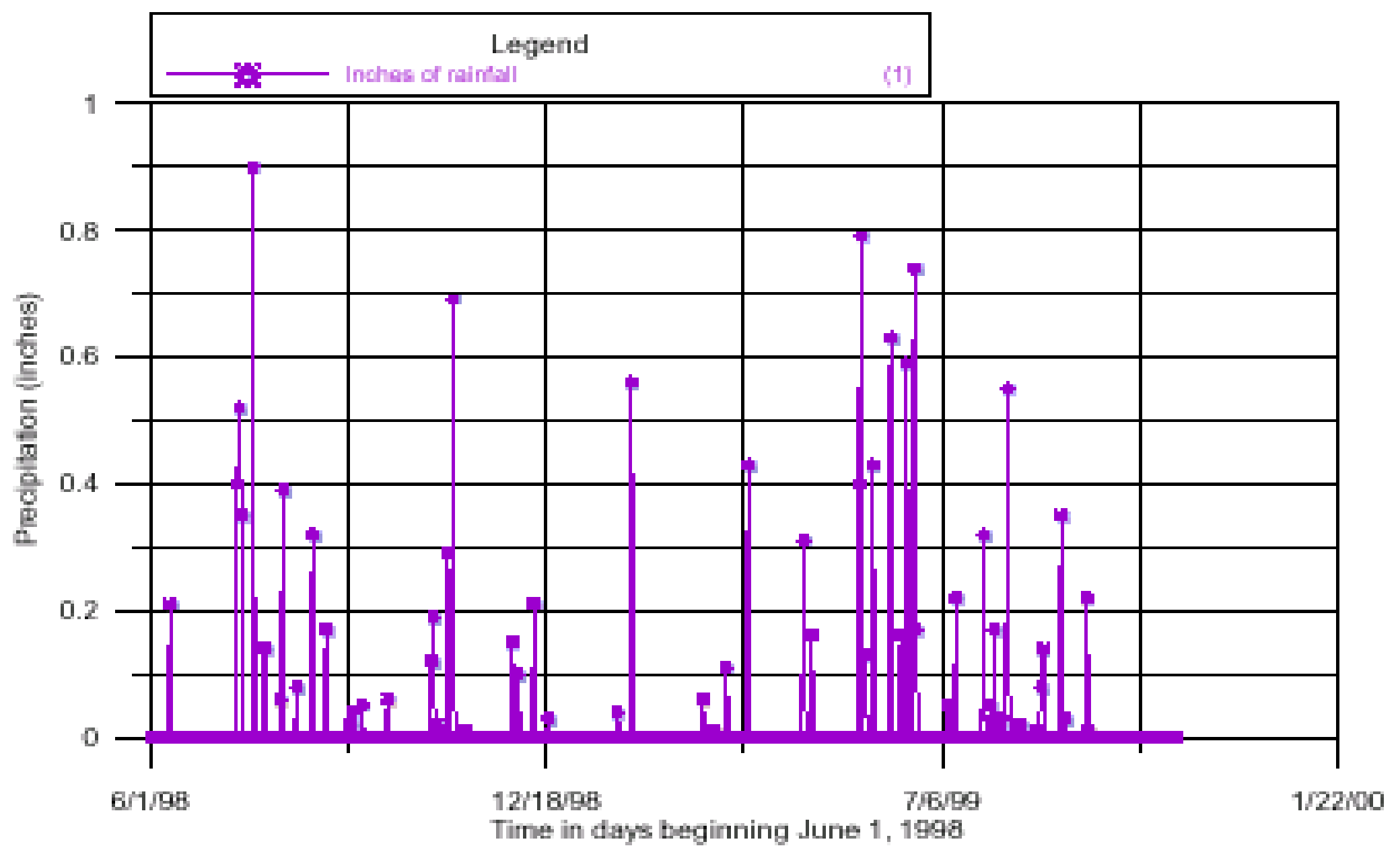

Figure 5-1. WPP sile precipitation: June "1 - October 31, 1999 


\subsection{DISCUSSION}

Sections 2.0 through 5.0 summarize factors effecting the reporting of fluid to the Exhaust Shaft Catch Basin over a 17-month period extending from June 1, 1998, through October 31, 1999. Section 6.0 attempts to clarify under what conditions fluid reports to the catch basin and what factors control fluid production.

Examination of the data from Sections 2.0 through 5.0 indicates that airflow is the primary factor controlling the quantity of the fluid reporting to the Exhaust Shaft Catch Basin. At the same time, relative humidity and ventilation system operations are secondary factors that can have a significant effect on fluid production depending on the present conditions in the shaft.

Figure 2-1 identifies three airflow periods: (1) June through October 1998, (2) November 1998 through April 1999, and (3) May through October 1999. The average airflow for those periods was $216,000,256,000$, and 343,000 CFM, respectively. During June through October 1998 the Exhaust Shaft Ventilation was impacted by major reductions in airflow. During the 152-day period there were 68 days of reduced airflow resulting in a reduction in the average airflow rate to 44,000 CFM/day. Figure 6-1 is a plot of airflow, precipitation, and volume of fluid removed from the catch basin. There were 20 days on which an estimated 9,715 gallons of fluid were removed from the catch basin. All 20 days were associated with reductions in airflow. This may not be intuitively obvious from the plot, but remember that fluid collected on a Monday may be the result of fluid reporting to the catch basin as much as 72-hours or more earlier. In addition, any fluid reporting to the catch basin would be affected by ventilation operations until it is removed. When correlating airflow and catch basin data, the airflow rate over the previous few days must be taken into consideration.

Figure 6-2 is a plot of hours of no airflow, reduced airflow, precipitation and catch basin data. This system's operation plot is helpful in that it defines windows of reduced airflow when fluid is more likely to report to the catch basin. At the same time, the plot also reveals periods of reduced airflow in which no fluid reports to the catch basin. As mentioned earlier, all 20 incidences of fluid reporting to the catch basin are associated with periods of reduced airflow. There are, however, several periods of reduced airflow in September and October 1998 where no fluid reported to the catch basin. This suggests that other factors, such as, humidity and ventilation operation, play contributing roles of varying importance.

Figure 6-3 is a plot of humidity, precipitation and catch basin flow data. As noted earlier, there were 20 days on which fluid was removed from the catch basin. Of those, only six exceeded 90 percent relative humidity. On the other hand, there were 32 days where the relative humidity exceeded 90 percent with no fluid apparently reporting to the catch basin. High humidity or extended periods of high humidity do not guarantee that fluid will report to the catch basin. For example, in late October there were twelve consecutive days with relative humidity values greater than 90 percent, and yet the only incident of fluid reporting to the catch basin was associated with reduced airflow.

Airflow is the primary controlling factor regulating the production and reporting of fluid to the catch basin. June 14 and June 22 provide examples illustrating the relative 
importance of airflow. Both cases are characterized by an extended period of reduced airflow and low relative humidity averaging less than 30 percent, leading up to fluid reporting to the catch basin. In both incidences the average airflow rate dropped to below 100,000 CFM. Careful examination of Figure 6-1 indicates that there were ten periods in which the average airflow rate decreased to below 100,000 CFM. Seven of the ten periods resulted in fluid reporting to the catch basin. Three did not. Why? The data suggests that the answer involves ventilation operation. Of the seven periods that resulted in fluid reporting to the catch basin all seven periods were preceded by a variable history of airflow dominated by extended periods of low airflow (less than $100,000 \mathrm{CFM}$ ). On the other hand, the three no-fluid reporting events that occurred in late September and early October 1999 are preceded by 22 days of alternate airflow $(260,000 \mathrm{CFM})$. This suggests that extended periods of alternate airflow may increase the capacity of the Exhaust Shaft to absorb or otherwise divert fluid from the catch basin during periods of reduced airflow.

A reasonable conceptual model must include a variety of mechanisms and behaviors. One, fluid seeps into the shaft from cracks in the shaft liner providing a relatively constant input. This fluid is absorbed into the shaft wall (depending on moisture content of the wall and host rock), taken up by the airflow, or reports to the catch basin. Two, air of varying humidity is pumped underground and then vented to the surface through the Exhaust Shaft. Depending on the velocity and the relative humidity of the air several possible scenarios can arise. If airflow is in alternate mode (260,000 CFM) or more and the relative humidity is low no fluid is likely to report to the catch basin and the moisture content of the walls would decrease or at least stabilize. An airflow rate of 260,000 CFM or greater appears to have the capacity consistently to prevent any fluid from reporting to the catch basin. If the relative humidity increases, the moisture content of the shaft wall will also likely increase. Even so, the example of the twelve-day period of high humidity in late October 1999 suggests that as long as the airflow is sustained at 260,000 CFM or higher, the ventilation system has the capacity to prevent most fluid from reporting to the catch basin. On the other hand, if the humidity is high and the airflow is reduced to below 100,000 CFM, there is a high probability that fluid will report to the catch basin. Therefore, management of the ventilation-system operation, the decision-making process of deciding when to reduce airflow and under what conditions, is an important factor to reducing the volume of fluid generated.

The question may arise with regards as to why more fluid is produced on some days than others, when the apparent conditions might suggest otherwise. As noted earlier, part of the answer lies in the condition of the shaft in the period leading up to an event. Prolonged periods of high airflow and low humidity followed by several days of airflow below 100,000 CFM may generate little, if any fluid because of the initially low moisture content of the shaft walls. However, if the humidity in the shaft has been high for an extended period of time, as it was in late September and October 1998, then the airflow may only have to be reduced slightly for a few hours to generate a very large quantity. Therefore, trying to predict or gage the relative amount of fluid that will be generated as a function of airflow, and humidity is difficult because it is a complex nonlinear, multi parameter relationship. In addition, there are other factors such as moisture content of the shaft walls and the salt in the shaft and the effects of salt dust from underground mine operations that vary in time and space that can have a significant impact on the 
reporting of fluid to the catch basin. Figure 6-4 is a plot of airflow, hours of no airflow, reduced airflow, precipitation and catch basin data for the period extending from May 1 through August 1, 1999. The average airflow rate was 309,000 CFM, 49,000 CFM above the alternate airflow rate for the Exhaust Shaft. During the 93-day period there were only six days of reduced airflow. Figure 6-4 indicates that there were thirteen events totaling 4,730 gallons of fluid that was removed from the catch basin. One event, on June 22, resulted in 1,705 gallons of fluid. Two other events, one on May 25 and the other on June 31, 1999, resulted in 605 gallons each. The other ten events accumulated less than 275 gallons each.

As mentioned previously, 95 percent of the fluid removed from the catch basin over the past seventeen months occurred between June 1 and October 31, 1998, and May 1 and August 1, 1999. Comparison of the two time intervals reveals some significant differences:

1. The average airflow rate between June 1 and October 31, 1998, was 216,000 compared to 309,000 CFM for May 1 through August 1, 1999, a difference of 93,000 CFM.

2. Between June 1 and October 31, 1998, there were 68 days of reduced airflow compared to only six days between May 1 and August 1, 1999.

3. All 20 events of fluid reporting the catch basin between June 1 and October 31 , 1998 , were associated with reduced airflow, as opposed to only two of thirteen events between May 1 and August 1, 1999.

4. Nine of 20 events between June 1 and October 31, 1998, attained relative humidity values greater than $80 \%$ while six of thirteen events between May 1 and August 1, 1999 attained relative humidity values greater than 80 percent.

Though airflow was maintained at a higher average, with few disruptions in ventilation of the Exhaust Shaft between May 1 and August 1, 1999, there appears to be an increase in

the number of incidences of fluid reporting to the catch basin under alternate mode airflow conditions (260,000 CFM). Comparison of Figures 6-3 (June 1 through October 31,1998 ) and Figure 6-5 (May 1 through August 1, 1999) do not indicate significant differences in the pattern or magnitudes of relative humidity leading up to the generation of fluid between May 1 and August 1, 1999.

There are some instances such as May 17 through June 1, 1999, where fluid reported to the catch basin (4 events totaling $\sim 1500$ gallons) during an extended period of relatively high humidity (averaged 60-65 percent, highs over 80 percent) and alternate mode airflow (260,000 CFM). But those humidity values were significantly lower than those which occurred during the 12-day period in late October 1998 discussed in section 6.1 (averaged $\sim 80$ percent, highs over 90 percent) when no fluid reported to the catch basin except during one day in which there was reduced airflow. Careful examination of the data tends to suggest that extended periods of high humidity (>60 percent) under alternate mode airflow conditions (260,000 CFM) can result in fluid 
reporting to the catch basin. If that is true, why is it that more fluid did not report to the catch basin in late October 1998. One possible explanation is that during the middle of the 12-day high-humidity period in late October 1998 the airflow was increased to 425,000 CFM. Figure 6-6 shows that there are no incidences of fluid reporting to the catch basin at an elevated airflow rate of 425,000 CFM. Operating at 425,000 CFM may provide high enough airflow to remove the fluid seeping into the Exhaust Shaft from the cracks in the shaft liner and fluid formed by the condensing of warm moisture laden air that is cooled as air rises in the shaft.

Figures 6-7 and 6-8 are comparisons of airflow, humidity, catch basin, and precipitation data for the period extending from November 1,1998, through April 30, 1999. The 182-day interval was a stable period of time when there were only three incidences of fluid reporting to the catch basin providing an excellent opportunity to verify some of the model parameters presented earlier. In early November 1998 there was an 11-day period of high humidity. Under alternate mode conditions, fluid should report to the catch basin, but in this situation there is no report of fluid. However, Figure 6-7 shows that during that eleven-day time interval there were eight days in which the airflow exceeded 330,000 CFM supporting the hypothesis that at high airflow rates result in no reporting of fluid. From Figures 6-7 and 6-8, around December 11, 1998, there is a tenday period of high humidity that is divided into periods of high airflow, reduced airflow, and high airflow. Once again, no fluid reports to the catch basin. The only significant event of fluid reporting to the catch basin on February 1, 1999 (385 gallons) after five days of high humidity coupled with several days of reduced airflow. Careful examination of relative humidity data shows that the five-day period of high humidity is preceded by several weeks of low humidity ( $\sim 35$ percent) during which time the moisture content of the shaft walls was decreasing. Though there are several days of high humidity and reduced airflow it took several days before fluid began reporting to the catch basin as the shaft walls resaturated.

Figures 6-7 and 6-8 indicate that during alternate mode airflow conditions $(260,000$ CFM), there is a low probability of fluid reporting to the catch basin unless there is an extended period of high humidity. 


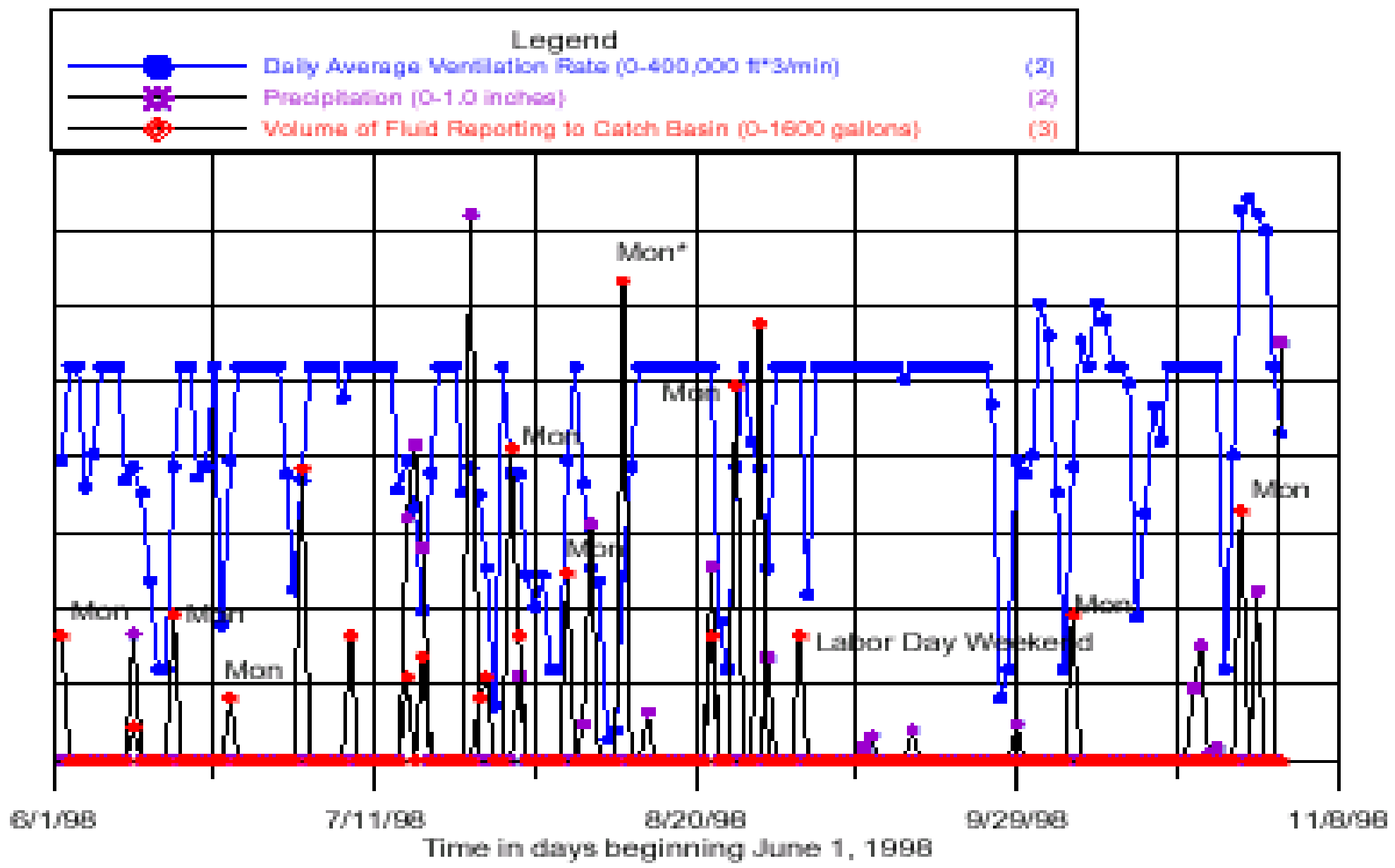

"Nobe Man a Brine removed an Manday

Figure 6-1. Ventilation, precipitation, and cateh basin data: June 1 - Ootober 31, 1998 

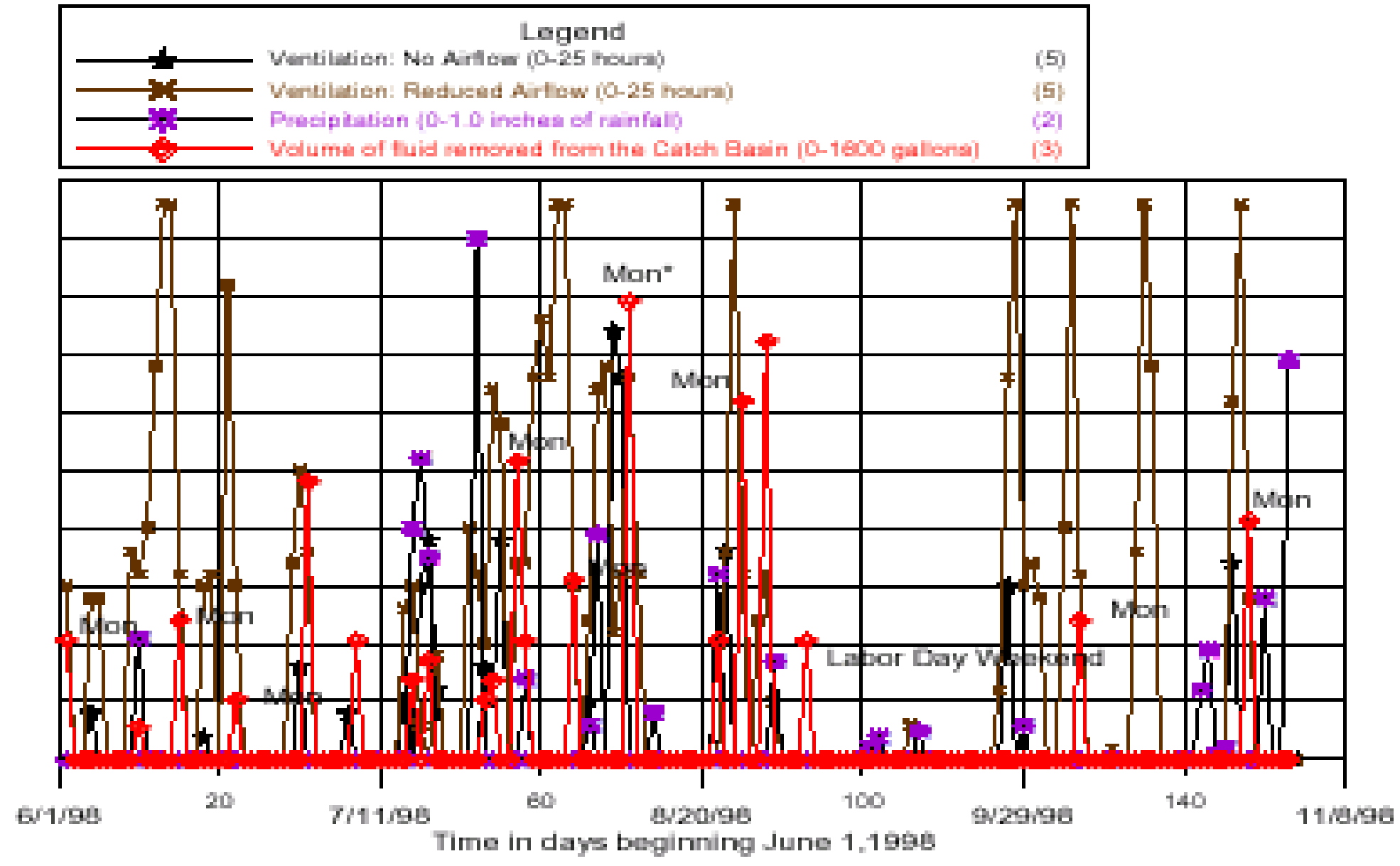

"Noto: Mon = Brino ramovad an a Manday

Figure 6.2. Hours no airflow, reduced airflow, site precipitation, and catch basin data: June 1 - Oetober 31, 1999 




Figure 6-3. Relativo humidity, precipitation, and cateh basin data: June 1 - Ottober 31 , 1996 




Figure 6-4_ Airflow Hours no flow, reduced airflow, precipitation, and catch basin data: May 1 - August 1, 1999 


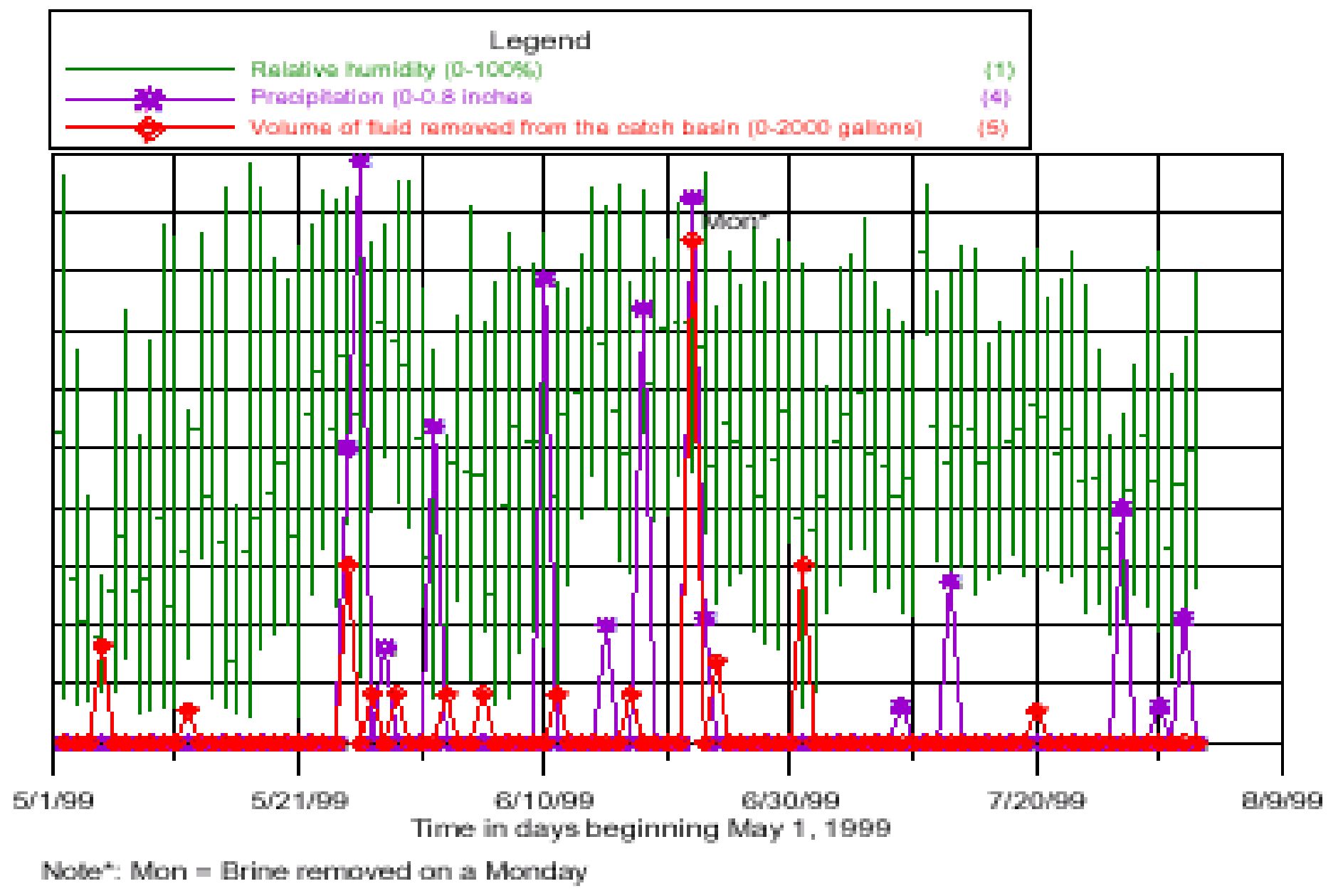

Figure 6-5. Relative humidity, precipitation, and eateh basin data: Vay 1 - August 1, 1999 


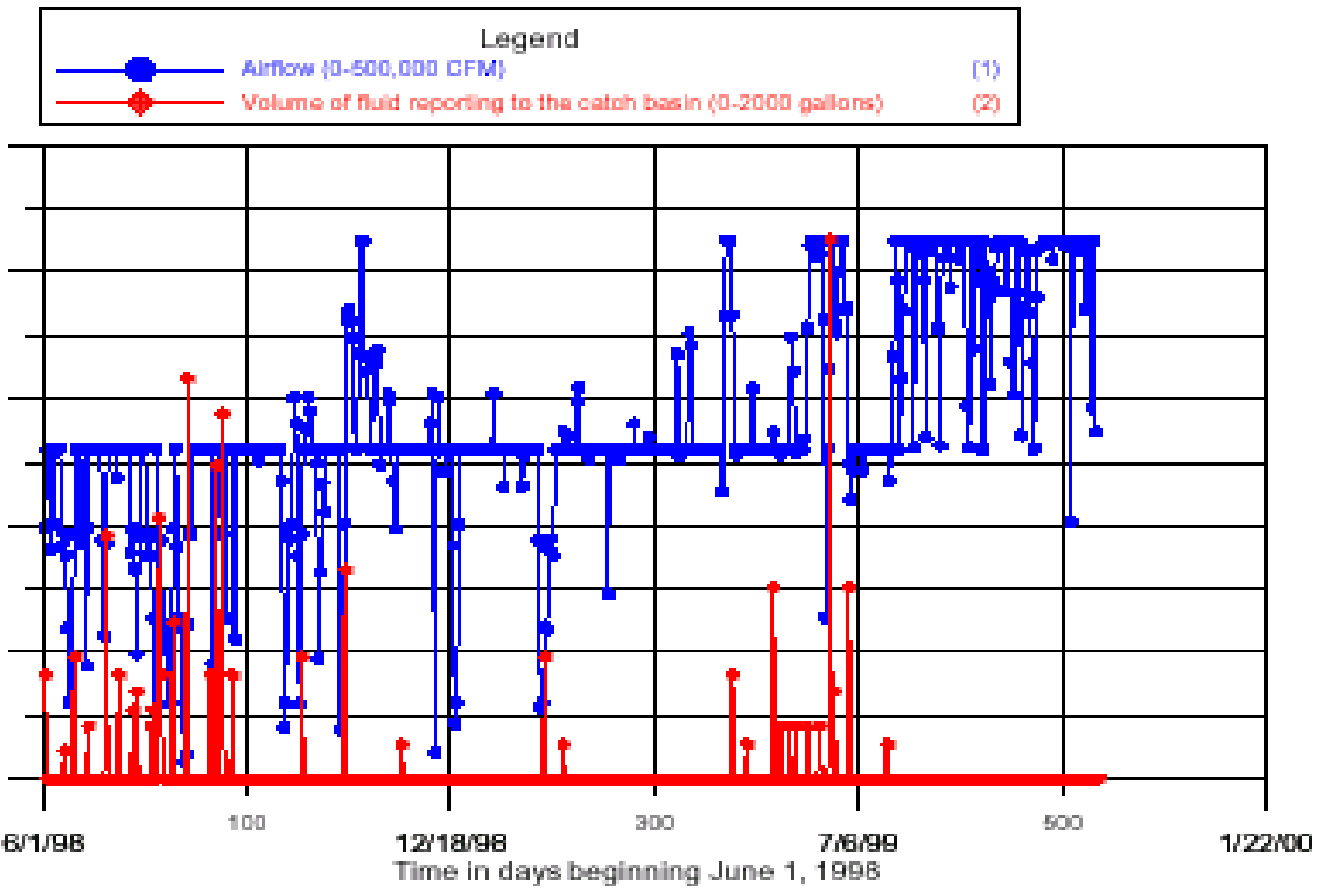

Fiqure 6-6. Airfow and eatch basin data June 1, 1990-Oetober 31, 1999 


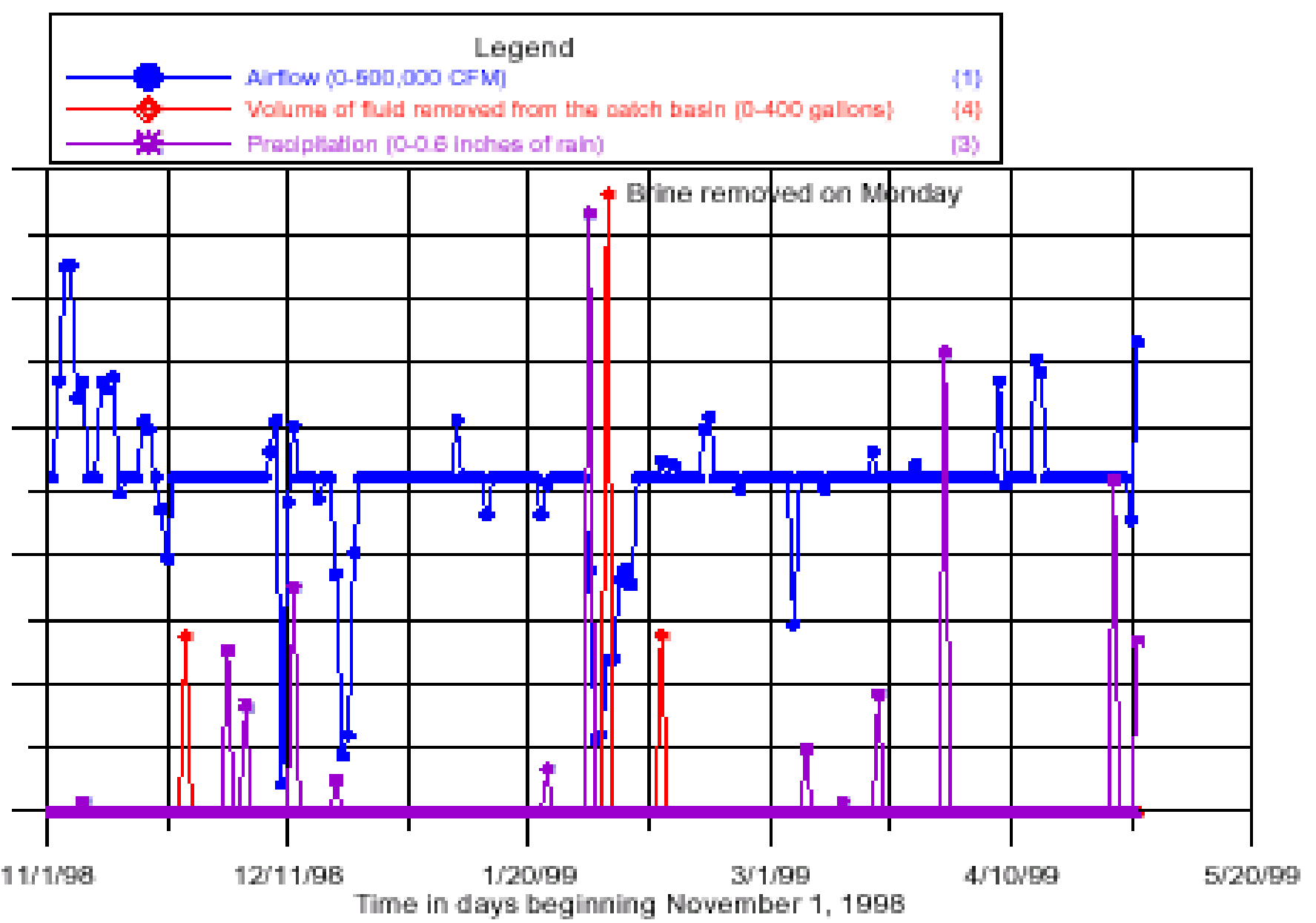

Figure 6-7. Aiffow, tateh bas'n and precipitation data: November 1, 1996 - April 30, 1999 


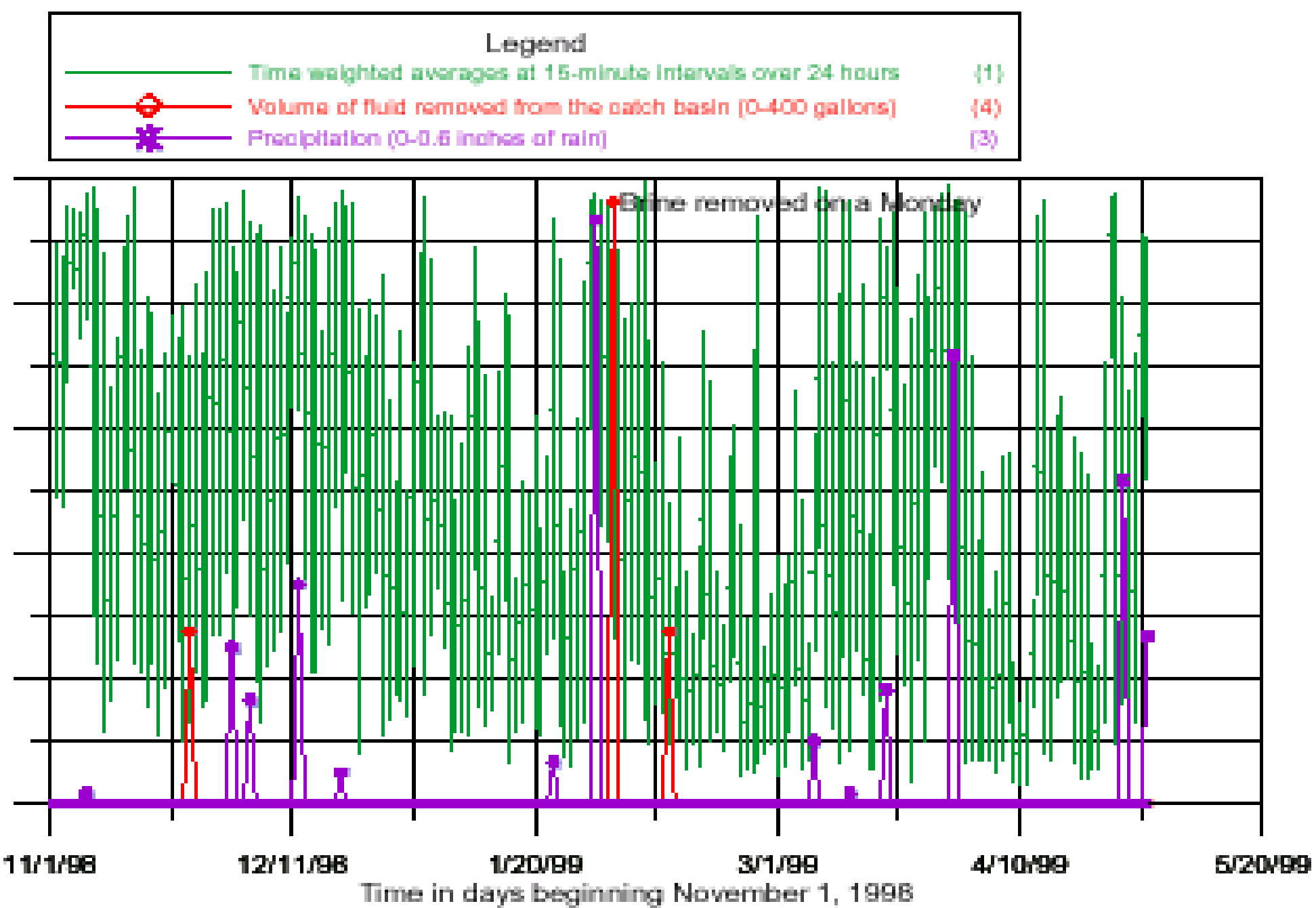

Figuro 6. Rolative humidity. procipitation, and cateh basin data: November 1, 1990 - April 30, 1999 


\subsection{CONCLUSION}

Seventeen months of Exhaust Shaft data related to airflow, relative humidity, ventilation operations, catch basin fluid volumes, and precipitation have provided important insight regarding the mechanisms effecting the quantity of fluid reporting to the Exhaust Shaft Catch Basin. From the 17 months of data, airflow is the primary factor controlling the quantity of fluid reporting.

At the same time though, humidity and system operations, the moisture content and the condition of the shaft walls also have a significant impact. As can be seen from the data, the problem is not simple, but highly complex, involving a number of variables that are nonlinear. There are however, several important findings that the data has revealed.

- $\quad$ First, there has been no recorded incident of fluid reporting to the catch basin when the ventilation is operating at full capacity $(425,000 \mathrm{CFM})$. This suggests that there is some value of airflow between 260,000 and 425,000 CFM that has the capacity to remove the fluid seeping into the Exhaust Shaft and the fluid that is generated from condensation by the cooling of warm moist laden air traveling up the shaft;

- Second, airflow can be maintained at 260,000 CFM for extended periods of time without fluid reporting to the catch basin provided the relative humidity does not exceed some threshold (appears to be $>60$ percent) for an extended period of time ( $>5$ days); and

- $\quad$ Third, operating at reduced airflow significantly increases the probability that fluid will report to the catch basin. The amount that reports is a function of the period of reduced airflow, the airflow rate, and the relative humidity. Even if the humidity is low, if there is an extended period of reduced airflow below 100,000 CFM, as occurred between June 1 and October 31, 1998, the probability of fluid reporting to the catch basin increases significantly.

Extended periods of high or low airflow or humidity effect the moisture content of the shaft walls, which can either attenuate or delay the reporting of fluid to the catch basin. Because the moisture content varies in time and place in the shaft it would be difficult to provide a representative value without considerable instrumentation.

System operations management can minimize the quantity of fluid reporting to the catch basin by effective tracking of the airflow, humidity, systems operation, extended weather forecasts and trend analysis. It is clear from the data that each of the parameters should be monitored daily and integrated into a real-time database in order to more effectively evaluate and control the conditions in the shaft. In addition, there are other parameters such as mining activities, which creates salt dust, and leaks in the WIPP site water system that may also impact Exhaust Shaft operations. These factors should also be examined more closely to determine the magnitude of their impact. 